Supplement of Atmos. Chem. Phys. Discuss., 15, 4879-4908, 2015

http://www.atmos-chem-phys-discuss.net/15/4879/2015/

doi:10.5194/acpd-15-4879-2015-supplement

(C) Author(s) 2015. CC Attribution 3.0 License.

(c) (i)

Supplement of

\title{
Increasing Arabian dust activity and the Indian Summer Monsoon
}

F. Solmon et al.

Correspondence to: F. Solmon (fsolmon@ictp.it) 
1 Supporting Information: Tables.

2

\begin{tabular}{|c|c|c|c|c|}
\hline Bin size $(\boldsymbol{\mu m})$ & $\mathbf{0 . 1} \mathbf{1}$ & $\mathbf{1 ~ - 2 . 5}$ & $\mathbf{2 . 5} \mathbf{- 5}$ & $\mathbf{5 ~ - ~ 2 0}$ \\
\hline $\begin{array}{c}\text { Extinction cross } \\
\text { section }(\mathbf{m} \mathbf{2} / \mathbf{g})\end{array}$ & 2.44 & 0.85 & 0.38 & 0.17 \\
\hline $\begin{array}{c}\text { Single Scattering } \\
\text { Albedo }\end{array}$ & 0.95 & 0.89 & 0.81 & 0.70 \\
\hline $\begin{array}{c}\text { Asymmetry } \\
\text { parameter }\end{array}$ & 0.64 & 0.76 & 0.81 & 0.87 \\
\hline
\end{tabular}

3

4 Table S1. Dust bin size and corresponding short wave optical properties for the visible band 5 (350-640 nm) of the RegCM model. 
2 Supporting Information: Figures.

3

4

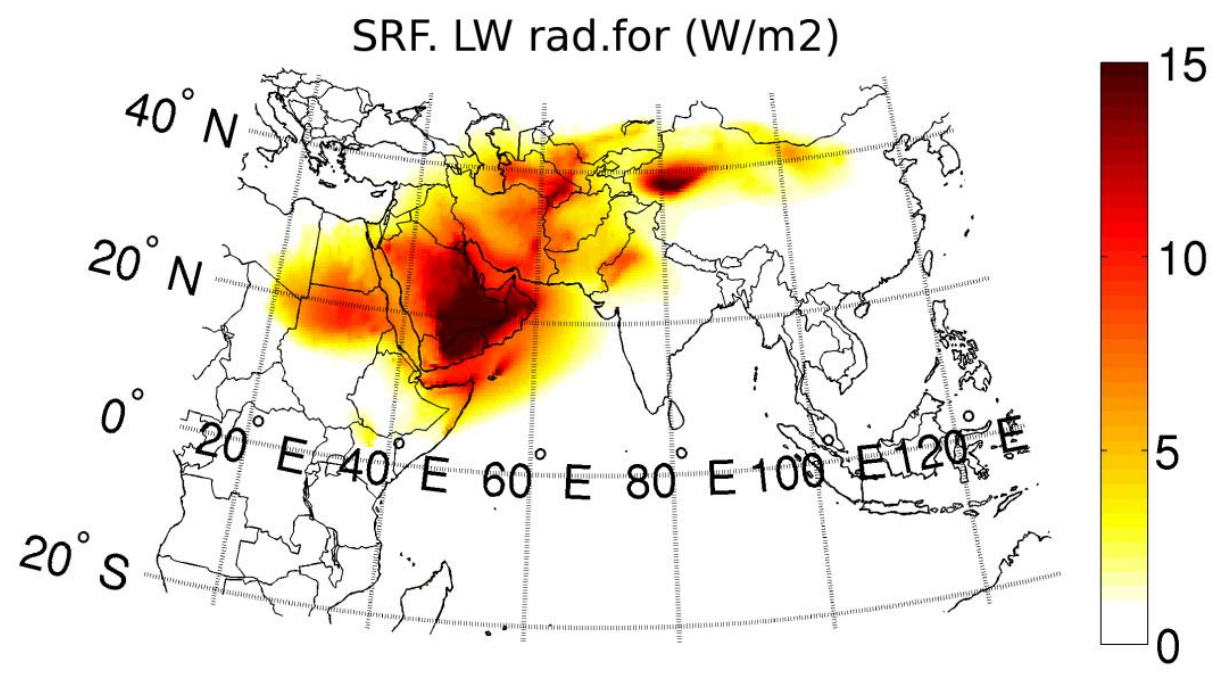

5

6 Figure S1. JJAS 2000-2009 dust surface long wave radiative forcing. 


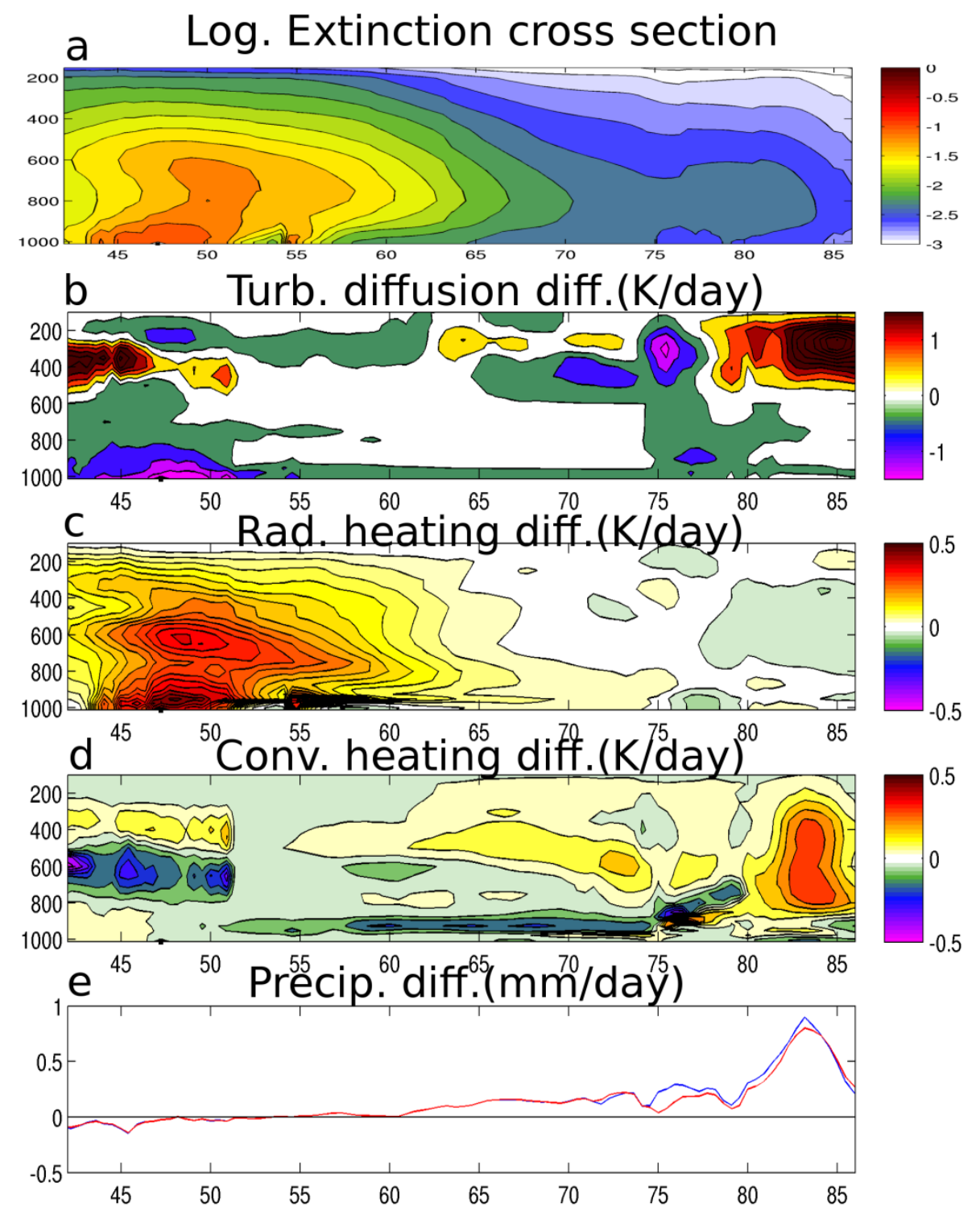

2 Figure S2. Zonal and vertical cross sections averaged between Latitude 5 and 15 N. (a) Mean 3 JJAS 2000-2009 extinction cross section (on a logarithm scale) of dust aerosols. (b) Mean JJAS

4 2000-2009 difference of turbulent heating rate between dust and nodust simulation. (c) Mean 5 JJAS 2000-2009 difference of radiative heating rate (SW +LW) between dust and nodust 6 simulation. (d) Mean JJAS 2000-2009 difference of convective heating rate between dust and 7 nodust simulation. (e) Precipitation difference between dust and nodust simulation. The red line 8 denotes convective precipitations, the blue line denotes total precipitations including convective 9 and stratiform percipitations. 


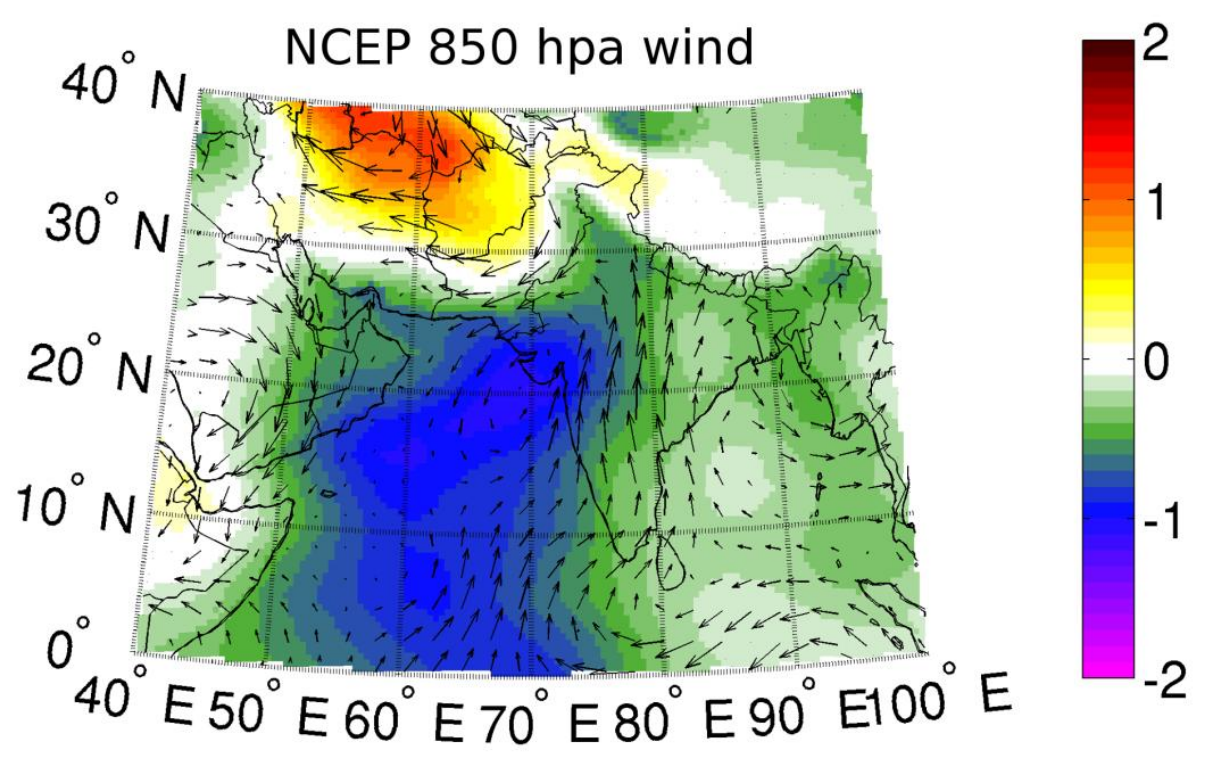

4 5

6 Figure S3. Difference of mean JJAS 850 hpa circulation and surface pressure between "dusty"

7 (2005-2009) and "less dusty" (2000-2004) pentads as defined in the text and calculated from

8 NCEP reanalysis, as a complement to manuscript figure 8.a. 